\title{
Temperature-induced control over phase selection among hydroxides of nickel
}

\author{
T N RAMESH* and P VISHNU KAMATH \\ Department of Chemistry, Central College, Bangalore University, Bangalore 560 001, India
}

MS received 12 September 2007; revised 16 February 2008

\begin{abstract}
While at low $\left(4^{\circ} \mathrm{C}\right)$ temperatures, addition of ammonia to aqueous metal nitrate solutions induces the precipitation of $\alpha$-nickel hydroxide and at high $\left(25-65^{\circ} \mathrm{C}\right)$ temperatures, $\beta-\mathrm{Ni}(\mathrm{OH})_{2}$ is formed. The crystallinity of the product improves at higher temperatures of precipitation and the product obtained at $65^{\circ} \mathrm{C}$ is devoid of various disorders such as stacking faults, turbostraticity and interstratification. This provides a simple and efficient alternative to the hydrothermal synthesis of crystalline $\beta-\mathrm{Ni}(\mathrm{OH})_{2}$. The temperature induced control over phase selection provides direct experimental evidence for the metastability of $\alpha$-nickel hydroxide. Crystalline $\beta-\mathrm{Ni}(\mathrm{OH})_{2}$ is, however, a poor electrode material for alkaline secondary cells and exhibits a capacity of only $75 \pm 10 \mathrm{mAh} / \mathrm{g}$, against the theoretically expected $289 \mathrm{mAh} / \mathrm{g}$.
\end{abstract}

Keywords. Nickel hydroxide; crystallinity; disorder; ammonia precipitation.

\section{Introduction}

Nickel hydroxide is a positive electrode material of all nickel based alkaline secondary cells (Falk and Salkind 1969). It is generally prepared by precipitation from an aqueous nickel salt solution by the addition of a strong alkali such as $\mathrm{NaOH}$ (Hui et al 1995). The resultant hydroxide is usually in a highly disordered state. The disorder manifests itself in the non-uniform broadening of reflections observed in the powder X-ray diffraction (PXRD) patterns of the material (Barnard et al 1981; Delmas and Tessier 1997; Rajamathi et al 2000). It has been generally suggested that the incidence of various kinds of disorder bestows upon nickel hydroxide superior electrochemical properties (Bernard et al 1996; Tessier et al 1999; Jayashree et al 2000). Nickel hydroxide exhibits a variety of disorders such as point defects (Bernard et al 1996; Cornilsen et al 1990), stacking faults (Tessier et al 1999), turbostraticity and interstratification (Rajamathi et al 2000; Ramesh et al 2003a). We have been, for some time, interested in developing synthetic strategies that enable us to engineer specific predetermined disorders into nickel hydroxide and correlate them with the reversible discharge capacity (Bernard et al 1996; Ramesh et al 2003b, 2005). As a first step in this direction, it is imperative to develop a suitable methodology that yields 'perfectly' ordered crystalline nickel hydroxide.

Crystalline brucite-like $\beta-\mathrm{Ni}(\mathrm{OH})_{2}$ is generally prepared by prolonged $(24 \mathrm{~h})$ hydrothermal treatment $\left(120-180^{\circ} \mathrm{C}\right)$

\footnotetext{
*Author for correspondence (rameshtn77@yahoo.co.in)
}

of the poorly crystalline, freshly precipitated nickel hydroxide gel (Fievet and Figlarz 1975; Delmas and Tessier 1997). Other techniques of precipitation such as electrochemical nitrate reduction (McHenry 1967) and homogeneous precipitation by urea hydrolysis (Dixit et al 1996) have been reported to yield $\alpha$-nickel hydroxide, which is a hydrated version of the $\beta$-form.

Other precipitation reagents can also be used for the synthesis of nickel hydroxide. Genin et al (1991) used a weak base such as ammonia to affect the precipitation of nickel hydroxide and obtained $\alpha$-nickel hydroxide. As a part of our continuing interest in the synthesis of $\alpha$-nickel hydroxide (Dixit et al 1996; Jayashree and Kamath 1999), we reinvestigated the ammonia precipitation of nickel hydroxide. In this paper, we report the synthesis of highly crystalline $\beta-\mathrm{Ni}(\mathrm{OH})_{2}$ by ammonia precipitation at temperatures above $25^{\circ} \mathrm{C}$, but $\alpha$-nickel hydroxide at lower $\left(4^{\circ} \mathrm{C}\right)$ temperatures. However, the electrochemical performance of pasted electrodes comprising of crystalline $\beta$-nickel hydroxide is inferior to that of poorly crystalline $\beta$-nickel hydroxide. The poorly crystalline nickel hydroxide was obtained by cycling of $\alpha$-phase of nickel hydroxide in alkali.

\section{Experimental}

Ammonia $(2 \mathrm{M}, 100 \mathrm{~mL})$ was added at the rate of $5 \mathrm{~mL}$ $\mathrm{min}^{-1}$ to a nickel nitrate $(1 \mathrm{M}, 50 \mathrm{~mL})$ solution placed in a thermostat. Separate precipitation reactions were carried out at different temperatures $\left(4^{\circ} \mathrm{C}, 25^{\circ} \mathrm{C}\right.$ and $\left.65^{\circ} \mathrm{C}\right)$. We label these samples as $\mathrm{NH} 4, \mathrm{NH} 25$ and $\mathrm{NH} 65$, respectively. In all cases the blue nickel amine complex was 
formed in addition to a green precipitate of nickel hydroxide. The precipitation, was, therefore, not quantitative. In all the cases, the precipitates were aged in mother liquor for $18 \mathrm{~h}$ at the respective precipitation temperatures, filtered, washed copiously and dried at ambient temperature over $\mathrm{P}_{2} \mathrm{O}_{5}$. Nickel hydroxide was also prepared by the addition of nickel nitrate solution (1 M, $50 \mathrm{~mL})$ to $\mathrm{NaOH}(2 \mathrm{M}, 100 \mathrm{~mL})$ and green slurry obtained was hydrothermally treated in mother liquor at $170^{\circ} \mathrm{C}$ for $18 \mathrm{~h}$. The sample was designated as HT170.

All nickel hydroxide samples were characterized by wet chemical analysis as described elsewhere (Jayashree and Kamath 1999) to obtain their approximate formula. The nickel content was estimated by the DMG method. The $\mathrm{OH}^{-}$content was estimated by dissolving a known weight of the sample in excess acid and back titrating the excess against a standard $\mathrm{NaOH}$ solution using a $\mathrm{pH}$ meter. In case of $\mathrm{NH} 65$, the $\left[\mathrm{OH}^{-}\right] /\left[\mathrm{Ni}^{2+}\right]$ ratio was found to be 2. In instances of non-stoichiometry, the excess positive charge was made good by the inclusion of nitrate ions. The unaccounted weight was attributed to water to arrive at an approximate formula. TGA (lab. built system, heating rate, $5^{\circ} \mathrm{C} \mathrm{min}^{-1}$ ) and drying studies were carried out to determine the moisture content of the samples (Ramesh et al 2003b). The results of TGA studies were found to be consistent with the results of wet chemical analysis. PXRD patterns were obtained using a JEOL Model JDX8P powder $\mathrm{X}$-ray diffractometer $(\mathrm{Cu} / \mathrm{CoK} \alpha$ source, $\lambda=1.5418 / 1.79 \AA)$ and infrared spectra were obtained using a Nicolet Model Impact 400D FTIR spectrometer. Rietveld refinement was carried out on NH65 nickel hydroxide sample using the FullProf program (Rodriguez-Carvajal 2000). Cell parameters and atomic position coordinates were obtained from the literature (Greaves and Thomas 1986).

\subsection{Electrochemical studies: Preparation of pasted electrodes}

Electrodes were prepared by mixing the nickel hydroxide sample with graphite powder and an aqueous suspension of PTFE in the ratio of $0 \cdot 6: 03: 0 \cdot 1$. The mixtures were thoroughly ground to obtain a paste like consistency. This paste was pressed at $120 \mathrm{~kg} \mathrm{~cm}^{-2}$ on either sides of a nickel foam $(2.9 \times 2.3 \mathrm{~cm})$ support at ambient temperature. The electrodes were dried at $65^{\circ} \mathrm{C}$ and soaked in $6 \mathrm{M} \mathrm{KOH}$ for $24 \mathrm{~h}$ before being galvanostatically (current, $5.5 \mathrm{~mA}$; $21 \mathrm{~h}$ ) charged to $120 \%$ of the theoretical capacity computed for a $1 e^{-}$exchange $(289 \mathrm{mAh} / \mathrm{g})$. Nickel plates were used as counters and all potentials were measured using a $\mathrm{Hg} / \mathrm{HgO} / \mathrm{OH}^{-}(6 \mathrm{M} \mathrm{KOH})$ reference. These electrodes were then discharged at a current of $40 \mathrm{~mA}$ to a cut off voltage of $0 \mathrm{~V}$ at ambient temperature $\left(28-30^{\circ} \mathrm{C}\right)$. This discharge current was chosen to yield a $\mathrm{C} / 2$ rate for the expected theoretical capacity of the electrode. The actual discharge rate varied from $1 \cdot 2-0.5 \mathrm{C}$ depending on the charge storage capacities of different electrodes.

\section{Results and discussion}

Genin et al (1991) not only reported the synthesis of $\alpha$ nickel hydroxide by ammonia precipitation, but they also succeeded in intercalating a variety of anions, including long chain carboxylates between the hydroxide slabs. However, our attempts to reproduce the results of Genin et al (1991) always resulted in the formation of $\beta$ $\mathrm{Ni}(\mathrm{OH})_{2}$. This was a cause of considerable concern to us, until we realized that temperature can seriously affect the outcome of precipitation reactions. Genin et al (1991) had ignored the effect of temperature. Using a thermostated water bath, at $4^{\circ} \mathrm{C}$, ammonia-induced precipitation yielded $\alpha$-nickel hydroxide (sample NH4), an observation that matched with those of Genin et al (1991). But what was very striking was the precipitation of highly crystalline $\beta$ - $\mathrm{Ni}(\mathrm{OH})_{2}(\mathrm{NH} 25)$ at $25^{\circ} \mathrm{C}$ and above. In figure 1 we compare the PXRD patterns of NH4 with that of NH25. The NH4 has a low angle reflection at $7.6 \AA$ characteristic of

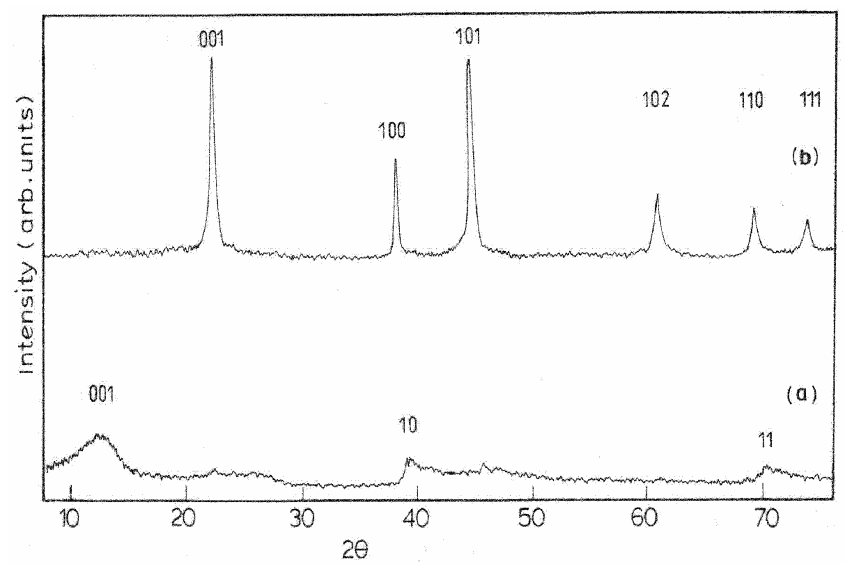

Figure 1. Powder X-ray diffraction patterns of the NH4 sample (a) compared with that of the NH25 sample (b).

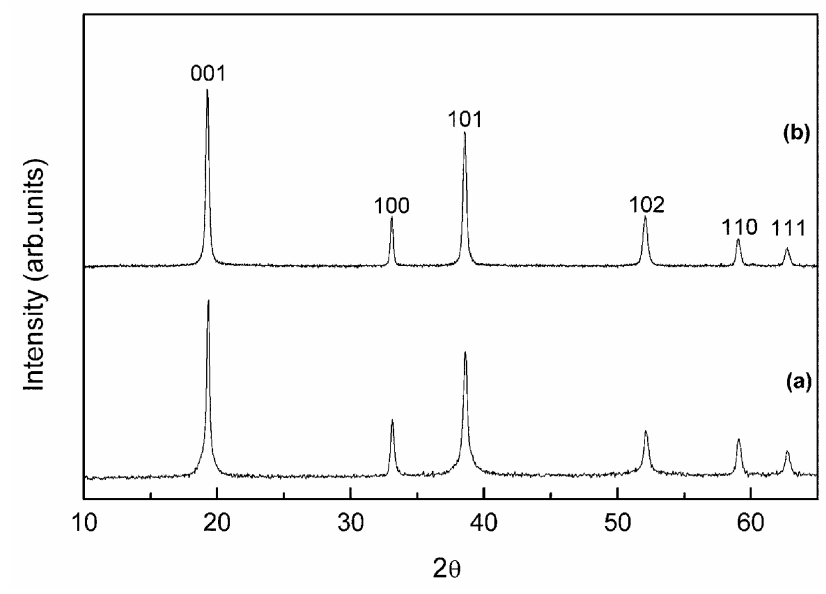

Figure 2. Powder X-ray diffraction patterns of a hydrothermally crystallized nickel hydroxide sample at $170^{\circ} \mathrm{C}$ (a) compared with that of the NH65 sample (b). 
Table 1. Parameters obtained from structure refinement by the Rietveld method. (a) Space group: $P-3 m 1$.

\begin{tabular}{|c|c|c|c|c|c|c|c|c|c|}
\hline \multirow[b]{2}{*}{ Sample } & \multirow[b]{2}{*}{$z$-position of the $\mathrm{O}$ atom } & \multicolumn{4}{|c|}{ Profile parameters } & \multicolumn{4}{|c|}{$\begin{array}{l}\text { Conventional Rietveld factors for } \\
\text { points with Bragg contribution }\end{array}$} \\
\hline & & $U$ & $V$ & $W$ & $\eta$ & $R_{\mathrm{wp}}$ & $R_{\mathrm{B}}$ & $\chi^{2}$ & DW-stat \\
\hline NH65 & $0 \cdot 2167$ & $0 \cdot 5990$ & $-0 \cdot 3355$ & $0 \cdot 1071$ & 0.7843 & $9 \cdot 80$ & $3 \cdot 02$ & 2.09 & 1.9813 \\
\hline
\end{tabular}

(b) Cell dimensions and thermal parameters

\begin{tabular}{lccc}
\hline Sample & $B_{\text {ov }}(\AA)^{2}$ & $a(\AA)$ & $c(\AA)$ \\
\hline NH65 & 2.4313 & $3 \cdot 130(2)$ & $4.615(4)$ \\
\hline
\end{tabular}

Table 2. Results of wet chemical analysis of nickel hydroxide samples.

\begin{tabular}{|c|c|c|c|c|c|c|}
\hline \multirow[b]{2}{*}{ Sample } & \multicolumn{4}{|c|}{ Weight percentage } & \multirow[b]{2}{*}{ Total weight loss ${ }^{\dagger}(\%)$} & \multirow[b]{2}{*}{ Approximate formula } \\
\hline & $\mathrm{Ni}^{2+}$ & $\mathrm{OH}^{-}$ & $\mathrm{NO}_{3}^{-}$ & $\mathrm{H}_{2} \mathrm{O}$ & & \\
\hline NH4 & $52 \cdot 00$ & $28 \cdot 54$ & $6 \cdot 04$ & $13 \cdot 41$ & $32 \cdot 03(33 \cdot 75)$ & $\mathrm{Ni}(\mathrm{OH})_{1 \cdot 89}\left(\mathrm{NO}_{3}\right)_{0 \cdot 11} \cdot 0 \cdot 84 \mathrm{H}_{2} \mathrm{O}$ \\
\hline $\mathrm{NH} 25$ & $58 \cdot 24$ & $32 \cdot 32$ & $3 \cdot 69$ & 5.746 & $24 \cdot 18(26 \cdot 16)$ & $\mathrm{Ni}(\mathrm{OH})_{1 \cdot 94}\left(\mathrm{NO}_{3}\right)_{0.06} \cdot 0 \cdot 32 \mathrm{H}_{2} \mathrm{O}$ \\
\hline NH65 & $61 \cdot 81$ & $35 \cdot 68$ & - & $2 \cdot 52$ & $20 \cdot 46(21 \cdot 45)$ & $\mathrm{Ni}(\mathrm{OH})_{2 \cdot 0} \cdot 0 \cdot 133 \mathrm{H}_{2} \mathrm{O}$ \\
\hline HT170 & $61 \cdot 76$ & $35 \cdot 40$ & - & $2 \cdot 46$ & $21 \cdot 6(21 \cdot 4)$ & $\mathrm{Ni}(\mathrm{OH})_{2 \cdot 0} \cdot 0 \cdot 13 \mathrm{H}_{2} \mathrm{O}$ \\
\hline
\end{tabular}

${ }^{\dagger}$ Values in parentheses are calculated on the basis of the approximate formula

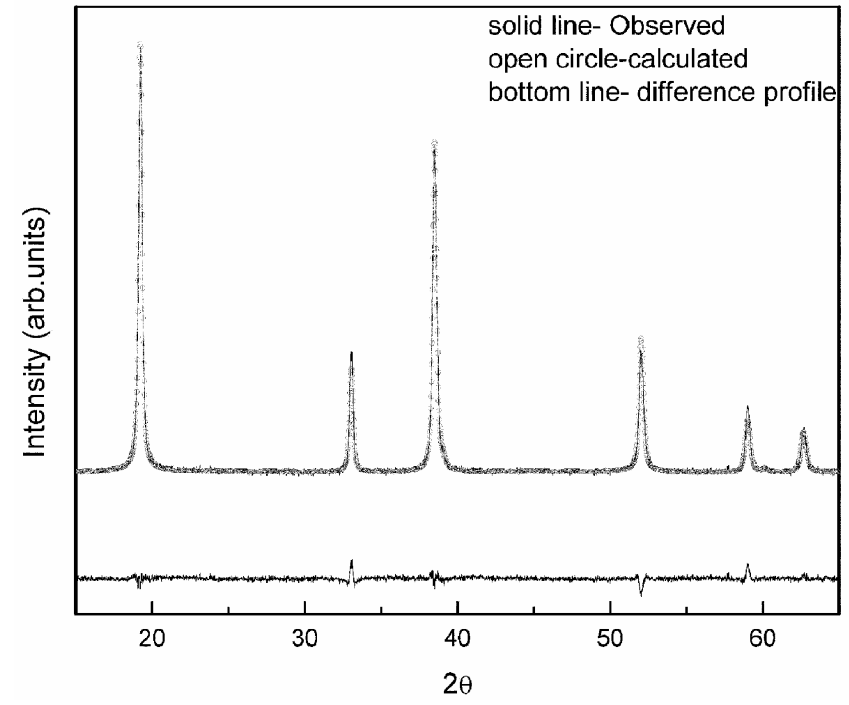

Figure 3. Result of the Rietveld refinement of the PXRD pattern of NH65 nickel hydroxide: observed (solid line), refined (open circle). The lower trace is the error function.

the interlayer distance of $\alpha$-nickel hydroxide. NH25 shows all the reflections characteristic of $\beta-\mathrm{Ni}(\mathrm{OH})_{2}$ (JCPDS PDF No. 14-117). In figure 2 we compare the PXRD pattern of NH65 with that obtained for the hydrothermally synthesized sample $\left(170^{\circ} \mathrm{C}, 18 \mathrm{~h}\right)$. In contrast to poorly crystalline samples obtained by strong alkali precipitation (Jayashree et al 2000), NH65 exhibits sharp peaks comparable with that of the hydrothermally synthesized sample.

In figure 3 is shown the result of structure refinement of NH65 sample using the Rietveld method. The refined atomic position coordinates and goodness of fit values are given in table 1 . The atomic coordinates and $\mathrm{Ni}-\mathrm{O}$ bond length are in close agreement with the values reported by Greaves and Thomas (1986). The goodness of fit values are in the acceptable range considered by Young (1993). From Rietveld refinement of $\mathrm{NH65}$, there is a reasonable evidence to suggest that the NH65 nickel hydroxide sample is highly crystalline and devoid of stacking faults, turbostraticity and interstratification which are ubiquitous in other preparations of nickel hydroxide. Ammonia precipitation can, therefore, be used as an energy efficient alternative to prolonged hydrothermal treatment.

Wet chemical analysis read together with thermogravimetric data and drying studies (see table 2) indicate that the NH65 sample is a stoichiometric hydroxide having the formula, $\mathrm{Ni}(\mathrm{OH})_{2}$ and contains only $1-2 \%$ by weight moisture. NH4 is hydroxide deficient and intercalates anions and water molecules (observed moisture content, 6.4\%), as expected of $\alpha$-nickel hydroxide.

Transmission electron micrographs of the $\mathrm{NH} 4$ and NH65 samples are shown in figure 4. It is clear that while NH4 exhibits turbostratic disorder similar to the samples reported by Genin et al (1991), NH65 exhibits platelet morphology.

Pasted electrodes comprising of the NH65 sample were electrochemically cycled for the determination of their reversible charge storage capacity. The stabilized capacity was found to be only $75 \pm 10 \mathrm{mAh} \mathrm{g}^{-1}$ of active material $(0.26 e / \mathrm{Ni}$ atom). In contrast, the $\mathrm{NH} 4$ samples yield $175 \mathrm{mAh} \mathrm{g}^{-1}(0.6 \mathrm{e} / \mathrm{Ni}$ atom) (figure 5$)$. This low capacity of NH65 is in keeping with earlier observations made on crystalline materials by other workers (Acharya et al 1993; Tessier et al 1999; Jayashree et al 2000). NH4 ( $\alpha$-phase) 

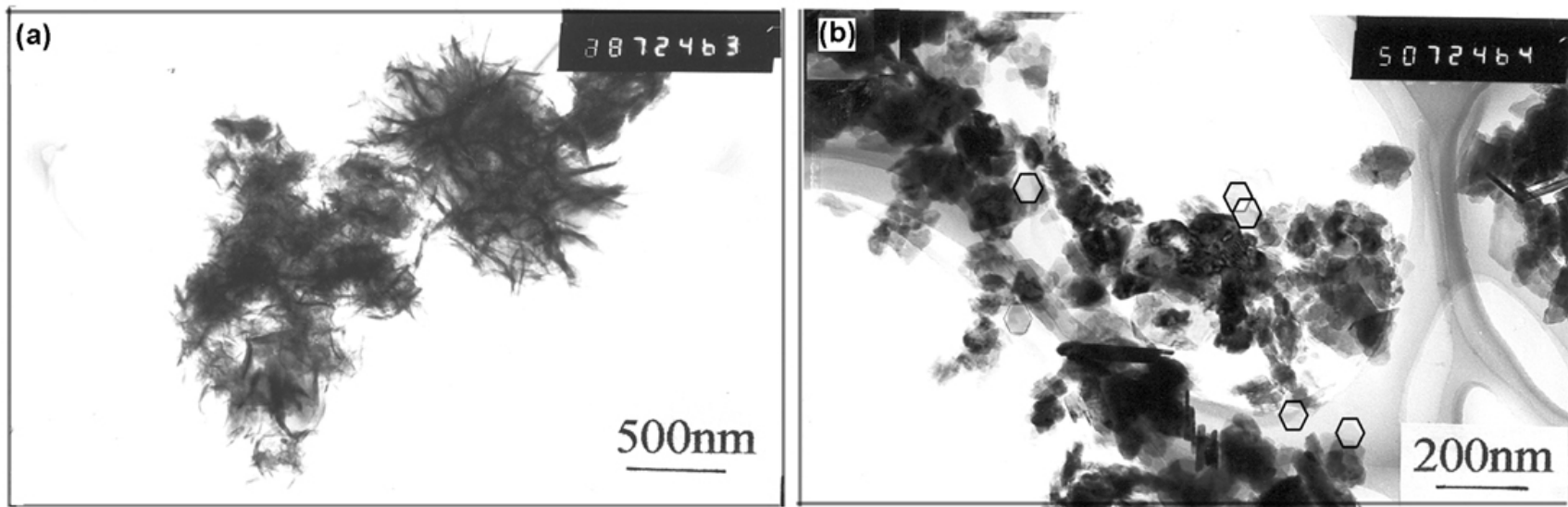

Figure 4. HRTEM image of the crystallites of NH4 (a) and NH65 (b) samples.

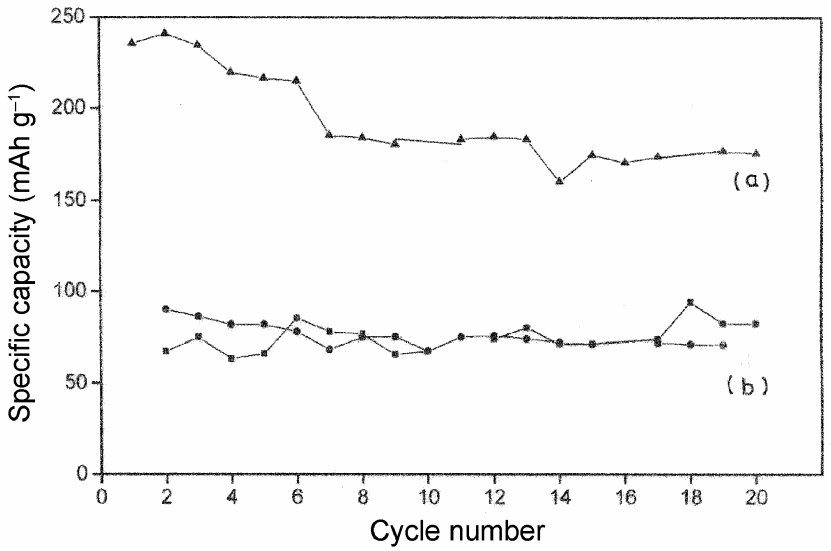

Figure 5. Cycle life data of the pasted electrodes comprising of the NH4 (a) and NH65 (b) samples.

being a metastable phase transforms into poorly crystalline $\beta$-nickel hydroxide on cycling in $6 \mathrm{M} \mathrm{KOH}$ at ambient temperature $\left(28-30^{\circ} \mathrm{C}\right)$. This is directly evident from the marginal decrease in the electrochemical performance of NH4 sample (see figure 5(a)). It is generally suggested that structural disorder/poor crystallinity enhances the charge storage capacity of nickel hydroxide.

\section{Conclusions}

The precipitation of $\alpha$-nickel hydroxide at low $\left(<4^{\circ} \mathrm{C}\right)$ temperature and of $\beta-\mathrm{Ni}(\mathrm{OH})_{2}$ at high $\left(>25^{\circ} \mathrm{C}\right)$ temperature provides direct experimental evidence for the metastability of the $\alpha$-modification.

\section{Acknowledgements}

The authors thank the Solid State and Structural Chemistry Unit and the Materials Research Centre, Indian Institute of Science, Bangalore, for powder X-ray diffraction and electron microscopy facilities, respectively. One of the authors (TNR) acknowledges the Council of Scientific and Industrial Research, Government of India, for the award of a Senior Research Fellowship (NET).

\section{References}

Acharya R, Subbaiah T, Anand S and Das R P 2002 J. Power Sources 109494

Barnard R, Randell C F and Tye F L 1981 Power sources (London: Academic Press) p. 409

Bernard M C, Cortes R, Keddam M, Takenuoti H, Bernard P and Senyarich S 1996 J. Power Sources 63247

Cornilsen B C, Shan X and Loyselle P L 1990 J. Power Sources 29453

Delmas C and Tessier C 1997 J. Mater. Chem. 71439

Dixit M, Subbanna G N and Kamath P V 1996 J. Mater. Chem. 61429

Falk S U and Salkind A J 1969 Alkaline storage batteries (New York: John Wiley \& Sons)

Fievet F and Figlarz M 1975 J. Catal. 391350

Genin P, Delahaye-Vidal A, Portemer F, Tekaia-Elhsissen K and Figlarz M 1991 J. Solid State Inorg. Chem. 28505

Greaves C and Thomas M A 1986 Acta Crystallogr. B42 51

Hui L, Yunchang D, Jiongliang Y and Zeyun W 1995 J. Power Sources 57137

Jayashree R S and Kamath P V 1999 J. Appl. Electrochem. 29449

Jayashree R S, Kamath P V and Subbanna G N 2000 J. Electrochem. Soc. 1472029

McHenry E J 1967 Electrochem. Technol. 5275

Rajamathi M, Kamath P V and Seshadri R 2000 J. Mater. Chem. 10503

Ramesh T N, Jayashree R S and Kamath P V 2003a Clays \& Clay Miner. $\mathbf{5 1} 570$

Ramesh T N, Jayashree R S and Kamath P V 2003b J. Electrochem. Soc. 150520

Ramesh T N, Kamath P V and Shivakumara C 2005 J. Electrochem. Soc. 152806

Rodriguez-Carvajal J 2000 Laboratoire Leon Brillouin, http:// www-llb.cea.fr/fullweb/powder.htm.

Tessier C, Haumesser P H, Bernard P and Delmas C $1999 \mathrm{~J}$. Electrochem. Soc. 1462059

Young R A (ed.) 1993 The Rietveld method (International Union of Crystallography, New York: Oxford University Press) 